\title{
Oak Kernels-Volatile Constituents and Coffee-Like Beverages
}

\author{
Sveto Rakić ${ }^{1}$, Jelena Kukić-Marković ${ }^{2}$, Silvana Petrović ${ }^{2}$, Vele Tešević ${ }^{3}$, Snežana Janković ${ }^{4}$ \\ $\&$ Dragan Povrenović ${ }^{5}$ \\ ${ }^{1}$ Faculty of Agriculture, University of Belgrade, Belgrade, Serbia \\ ${ }^{2}$ Faculty of Pharmacy, University of Belgrade, Belgrade, Serbia \\ ${ }^{3}$ Faculty of Chemistry, University of Belgrade, Belgrade, Serbia \\ ${ }^{4}$ Institute for Science Application in Agriculture, Belgrade, Serbia \\ ${ }^{5}$ Faculty of Technology and Metallurgy, University of Belgrade, Belgrade, Serbia \\ Correspondece: Sveto Rakić, Faculty of Agriculture, University of Belgrade, Belgrade, Serbia. E-mail: \\ sveto@agrif.bg.ac.rs
}

Received: January 11, 2018

Accepted: March 8, $2018 \quad$ Online Published: April 15, 2018

doi:10.5539/jas.v10n5p117

URL: https://doi.org/10.5539/jas.v10n5p117

\begin{abstract}
Modern consumers are much aware of potential health benefits of food and food ingredients. The food industry has been constrained to develop new products with improved sensory, nutritive and functional characteristics. In this work a potential use of English (Quercus robur) and Turkish oak (Quercus cerris) kernels as functional food components was estimated. Volatiles from native and roasted kernels were isolated using continuous hydro distillation with $\mathrm{CH}_{2} \mathrm{Cl}_{2}$ and analyzed with $\mathrm{GC} / \mathrm{MS}$. Coffee-like beverages were prepared from roasted kernels of both species and a sensory assessment was conducted. In the native samples the main compounds were beta-eudesmol and palmitic acid (39.9 and 24.9\%, respectively) in $Q$. robur, and palmitic acid $(53.8 \%)$ in $Q$. cerris. In the roasted samples the main compounds were furans: furfural (51.7 and 60.6\%) and 5-methyl-furfural ( 8.6 and $9.4 \%$, respectively). Coffee-like beverages from roasted oak samples were evaluated for sensory properties gaining high scores for appearance, with satisfying taste and fullness. The presented results, along with previous findings on substantial antioxidant and antiradical activities of English and Turkish Oak kernels, draw attention to these easy available, cheap, but neglected native raw materials as valuable functional food components. Further investigations on this matter are warranted.
\end{abstract}

Keywords: Quercus robur, Quercus cerris, volatiles, coffee-like beverages, sensory assessment

\section{Introduction}

Modern consumers are much aware of potential health benefits of food and food ingredients, thus demand for products with certain functional properties is growing continuously. The food industry has been constrained to develop new products with improved sensory, nutritive and functional characteristics (Andrés, Dolores Tenorio, \& José Villanueva, 2015; Sakhale, Pawar, \& Ranveer, 2012).

The English and the Turkish oak (Quercus robur L. and Quercus cerris L., Fagaceae) are common species in European flora; the English oak is mainly found in plains and river valleys, and the Turkish oak in Southern Europe, particularly in the Apennine Peninsula and the Balkan Peninsula (Janković, 1975). The use of acorns of these, as well as of many other oak species in Europe, especially in the Mediterranean region (Italy and Spain) has been well documented. The holm oak (Quercus ilex L.) acorns are a major component in feeding systems of many Mediterranean wild and livestock species. Moreover, it is also the basic feed ingredient for domestically bred high-quality meat pigs (Valero Galván, Jorrín Novo, Cabrera, Ariza, García-Olmo, \& Cerrillo, 2012). In past times oak acorns were used in human nutrition, furnishing up to $25 \%$ of the food consumed by the poorer classes (Hill, 1937). They were mainly used for making bread (up to $10 \%$ of quantity) or roasted and used as a substitute for coffee (Fernald \& Kinsey, 1943). In Serbia, oak acorns have been used in human diet since $19^{\text {th }}$ century (Jevtović, 1980). Beside their nutritional significance, oak kernels (Quercus semen) particularly roasted ones (Quercus semen tostum) were used in traditional medicine, as astringent, antidiarrheal and antidote (Gorunović \& Lukić, 2001; Tucakov, 1971). 
Oak acorn kernels are rich in carbohydrates, amino acids, proteins, lipids and various sterols (Lopes \& Bernardo-Gil, 2005; Rakić, Povrenović, Tešević, Simić, \& Maletić, 2006; Rakić, Petrović, Kukić, Jadranin, Tešević, Povrenović, \& Šiler-Marinković, 2007). They have high energy value and are highly digestible (Saricicek \& Kilic, 2004). Kernel oils of the English and Turkish oak are characterized by high levels of oleic (over 40\%) and linoleic (over 30\%) acids (Cabrera-Vique, Marfil, Giménez, \& Martínez-Augustin, 2012; Petrović, Šobajić, Rakić, Tomić, \& Kukić, 2004) and are also valuable source of essential $\alpha$-linolenic acid (1.8 and 3.7\%, respectively) (Petrović et al., 2004). The acorn kernels of these two Quercus species beside nutritional components contain various biologically active compounds (tannins, gallic and ellagic acid, and different galloyl and hexahydroxydiphenoyl derivatives), that contribute to antioxidant properties, which were proven in various test models and comparable with some commercial antioxidants (Rakić, Maletić, Perunović, \& Svrzić, 2004; Rakić, Povrenović, Tešević, Simić, \& Maletić, 2006; Rakić, Petrović, Kukić, Jadranin, Tešević, Povrenović, \& Šiler-Marinković, 2007). That is one of the reasons why oak acorn kernels, especially the roasted ones, could be considered as functional food or functional food ingredients, since they may provide a health benefit beyond their nutritional value (Ferrari \& Torres, 2003).

In Serbia, oak kernels, along with chicory root and rye, are traditionally used as a cheap and easily available substitute for coffee (roasted, ground and extracted with hot water) (Gorunović \& Lukić, 2001; Tucakov, 1971). Coffee substitutes are becoming increasingly popular, mostly due to the absence of caffeine in brewed beverages. They could also be a source of diverse bioactive compounds, and are appropriate for consumption by consumers of all ages and consumers with medical issues (Komes, Bušić, Vojvodić, Belščak-Cvitanović, \& Hruškar, 2015). Organoleptic properties of such products, as well as any other food and beverages, have important influence on consumers' choice, so the sensory assessment becomes an important step in developing new food products (Raileanu, Lenco, \& Rotaru, 2009). Moreover, information on volatile compounds contributing to organoleptic properties of some products and on conditions that provide forming those specific characteristics, are very valuable. Considering oak volatiles, until now only those from native and thermally treated wood have been investigated (Nonier, Vivasa, Vivas de Gaulejac, Absalon, Soulié, \& Fouquet, 2006). The aim of this work was to estimate prospective use of the English and Turkish oak acorn kernels as functional food components. To achieve this, the volatile compounds of native and roasted kernels were investigated, coffee-like beverages obtained from the roasted kernels were prepared and their sensory assessment was conducted.

\section{Material and Methods}

\subsection{Plant Material}

Mature acorns of Q. robur (English oak) $(\mathrm{QR})$ were collected in central Serbia (from the Belgrade outer city area), while those of Q. cerris (Turkish oak) (QC) were collected in western Serbia (20 km south-eastern from Bajina Bašta). Only whole, undamaged acorns found on the ground were collected. The collected material was dried at $50{ }^{\circ} \mathrm{C}$ for 12 hours, and then the acorns were shelled out. The obtained samples represent dry native oak kernels (consisting of 2 endosperms) used for further investigations. The samples were deposited at room temperature prior to the investigation.

\subsection{Sample Preparation and Roasting}

One part of the native oak acorn kernels were cut in small pieces ( $3 \mathrm{~mm}$ mesh size) and ground in a multipractic apparatus (samples QRN and QCN). The thermal treatment consisted of "dry roasting" of the previously crushed native kernels, at $200{ }^{\circ} \mathrm{C}$ for 15 minutes (samples QRR and QCR). After roasting the samples were left to cool down. All the samples were packed in polyethylene bags, and stored at $5{ }^{\circ} \mathrm{C}$ before being analyzed.

\subsection{Isolation of Volatiles}

The native (QRN and QCN) and roasted (QRR and QCR) samples were extracted using simultaneous hydro distillation and the solvent extraction method with a Likens-Nickerson apparatus. Each sample $(10 \mathrm{~g})$ was mixed with $150 \mathrm{ml}$ of purified water and extracted with $7 \mathrm{ml} \mathrm{CH}_{2} \mathrm{Cl}_{2}$ during $2 \mathrm{~h}$. The obtained extracts were analyzed with GC-FID and GC-MS.

\subsection{GC-FID and GC-MS Analysis}

GC-FID analysis was performed under the following operating conditions: GC HP 5890 apparatus equipped with a flame-ionization detector (FID) and a split/splitless injector; a capillary column HP-5 $(30 \mathrm{~m} \times 0.25 \mathrm{~mm} ; 0.25$ $\mu \mathrm{m}$ film thickness); column temperature linearly programmed: $50{ }^{\circ} \mathrm{C}(6 \mathrm{~min})$ to $285^{\circ} \mathrm{C}$ with linear temperature growth $4.3^{\circ} \mathrm{C} / \mathrm{min}$; a carrier gas: $\mathrm{H}_{2}(1.6 \mathrm{ml} / \mathrm{min})$; the temperature of the injector: $250{ }^{\circ} \mathrm{C}$; the temperature of the detector $280^{\circ} \mathrm{C}$; splitless mode; the volume of the sample: $1.0 \mu 1$. 
GC-MS analysis was performed on an Agilent 6890 Network GC system fitted with Agilent 5973 MSD and equipped with a capillary column Agilent 19091S-433 HP-5MS (30 m $\times 0.25 \mathrm{~mm}$; $0.25 \mu \mathrm{m}$ film thickness); column temperature linearly programmed: $60-285{ }^{\circ} \mathrm{C}\left(4.3{ }^{\circ} \mathrm{C} / \mathrm{min}\right)$; a carrier gas: $\mathrm{He}(1 \mathrm{ml} / \mathrm{min})$; detector temperature: $210^{\circ} \mathrm{C}$; mass range: $40-250 \mathrm{D}$, with $11.47 \mathrm{scan} / \mathrm{min}$.

Identification of components was done only on the basis of retention index (RI) and by comparison with reference mass spectra (Wiley and NIST databases).

\subsection{Preparation and the Sensory Assessment of Coffee-Like Beverages}

Coffee-like beverages were prepared from the roasted samples (QRR and QCR), ground in a laboratory mill (1 $\mathrm{mm}$ mesh size). Each of the obtained samples $(35 \mathrm{~g})$ was mixed with distilled water $(600 \mathrm{ml})$ and extracted in a water bath under a flux condenser for 30 minutes after the sample started boiling. The extracts were filtered and then their sensory analysis was performed. Each experiment was run in triplicate, and the results were obtained as the main value.

The sensory tests were performed by 20 volunteer panelists, students and personnel from the Department of Food Technology and Biochemistry, Faculty of Agriculture, University of Belgrade. During the test, all the assayers were in a specially adapted chamber with adequate light. The beverages were served hot, at the temperature of about $60{ }^{\circ} \mathrm{C}$, in white cups encoded with 4 digits. Each beverage was evaluated for its sensory characteristics and key features: appearance, taste, aroma and fullness. The panelists assigned points for each of these characteristics using a numeric scale: appearance (1-3 points), taste (1-5 points), aroma (1-7 points) and fullness (1-5 points), so that overall maximal score of coffee-like beverage was 20 (Fadel, Mageed, \& Lotfy, 2008; ISO 3509, 2005; Kemp, Hollowood, \& Hort, 2011).

\section{Results and Discussion}

\subsection{Volatile Components}

In the native kernel samples a total of 24 volatiles were identified, 15 in QRN (92.0\%) and 16 in QCN (92.9\%) (Table 1). In QRN, the main volatile fraction was sesquiterpenes (55.3\%), with $\beta$-eudesmol (39.9\%) being the principal compound. Palmitic acid $(24.9 \%)$ was the second principal compound in this sample. The main component in QCN was palmitic acid (53.8\%), followed by oleic acid (9.2\%), phenylethanal (8.0\%) and 2.4-decadienal (7.1\%). 
Table 1. Volatile compounds of native and thermally treated acorn kernels of English Oak, Quercus robur and Turkish Oak, Q. cerris

\begin{tabular}{|c|c|c|c|c|c|c|}
\hline Compound & RT (min) & RI & QRN (\%) & QCN (\%) & QRR (\%) & QCR (\%) \\
\hline Hexanal & 6.5 & 809 & 0.7 & 1.2 & - & - \\
\hline 2-Methypyrazine & 7.3 & 818 & - & - & 2.3 & 3.4 \\
\hline Furfural & 7.7 & 832 & 1.9 & 1.4 & 51.7 & 60.6 \\
\hline 5-Methyl-2-furanone & 8.8 & 869 & - & - & 1.5 & 1.5 \\
\hline 2-Cyclopenten-1.4-dione & 9.3 & 891 & - & - & - & 0.5 \\
\hline 2-Ethylpyrazine & 9.7 & 912 & - & - & 0.6 & 2.4 \\
\hline 2-Acethylfurane & 9.8 & 915 & - & - & 1.2 & 2.4 \\
\hline 2.4-Dimethylpyrazine & 9.8 & 916 & - & - & - & 1.0 \\
\hline 4-Methyl furfural & 10.5 & 920 & - & - & 9.9 & - \\
\hline 5-Methyl furfural & 11.2 & 963 & - & - & 8.6 & 9.4 \\
\hline 2-Ethyl-2-methylpyrazine & 11.3 & 994 & - & - & $\operatorname{tr}$ & $\operatorname{tr}$ \\
\hline Tetrahydro-5.5-dimethyl-2-furanone & 11.5 & 995 & - & - & 1.1 & - \\
\hline 2-Ethyl-5-methylpyrazine & 11.7 & 998 & - & - & 0.5 & - \\
\hline 2-Ethyl-3-methylpyrazine & 11.9 & 999 & - & - & 0.3 & 1.3 \\
\hline 2.3-Dimethyl-ciclopenten-1-one & 13.0 & 1,040 & - & - & $\operatorname{tr}$ & - \\
\hline Phenylethanal & 13.1 & 1,044 & 2.9 & 8.0 & 0.5 & 0.5 \\
\hline 2-Octenal & 13.3 & 1,046 & - & $\operatorname{tr}$ & - & - \\
\hline 2.6-Diethylpyrazine & 13.5 & 1,083 & - & - & 0.5 & 2.0 \\
\hline 3-Ethyl-2.5-dimethylpyrazine & 13.6 & 1,088 & - & - & $\operatorname{tr}$ & $\operatorname{tr}$ \\
\hline Sotolone & 14.0 & 1,099 & - & - & 1.3 & 0.8 \\
\hline Nonanal & 14.0 & 1,106 & - & $\operatorname{tr}$ & - & - \\
\hline Phenylethyl alcohol & 14.5 & 1,121 & - & 2.0 & - & - \\
\hline Nonenal & 15.4 & 1,158 & - & $\operatorname{tr}$ & - & - \\
\hline Phenylethyl formate & 15.7 & 1,178 & - & - & - & 0.6 \\
\hline Decanal & 16.1 & 1,195 & - & $\operatorname{tr}$ & - & - \\
\hline 1.1-Dimethoxy-dodecane & 16.9 & 1,220 & - & - & 1.9 & - \\
\hline 2-Isoamyl-6-methylpyrazine & 17.0 & 1,248 & - & - & $\operatorname{tr}$ & $\operatorname{tr}$ \\
\hline 2-Coumaranone & 17.4 & 1,250 & - & - & $\operatorname{tr}$ & - \\
\hline 2.4-Decadienal & 18.6 & 1,315 & $\operatorname{tr}$ & 7.1 & - & - \\
\hline Buthylbenzoate & 19.3 & 1,377 & - & $\operatorname{tr}$ & - & - \\
\hline cis-Jasmone & 19.7 & 1,390 & - & - & - & 0.5 \\
\hline$\alpha$-Muurolene & 21.4 & 1,497 & 1.1 & - & - & - \\
\hline Lauric acid & 22.1 & 1,570 & - & - & - & 0.2 \\
\hline$\gamma$-Eudesmol & 23.7 & 1,632 & 3.0 & - & - & - \\
\hline Hinesol & 23.8 & 1,642 & - & 2.2 & - & - \\
\hline$\tau$-Cadinol & 23.9 & 1,638 & 3.6 & - & - & - \\
\hline$\alpha-$ Cadinol & 24.0 & 1,639 & 1.9 & - & $\operatorname{tr}$ & - \\
\hline$\tau$-Muurolol & 24.1 & 1,642 & 5.8 & - & 0.3 & - \\
\hline$\beta$-Eudesmol & 24.2 & 1,652 & 39.9 & 3.6 & 0.7 & $\operatorname{tr}$ \\
\hline$\gamma$-Dodecalakton & 24.5 & 1,673 & - & 0.8 & - & - \\
\hline Myristic acid & 25.0 & 1,765 & - & 3.6 & - & 0.2 \\
\hline Methylpalmitate & 27.2 & 1,931 & 1.0 & - & 3.3 & 0.3 \\
\hline Palmitic acid & 27.7 & 1,965 & 24.9 & 53.8 & 0.6 & 2.2 \\
\hline Methyllinoleate & 29.4 & 2,106 & - & - & 1.5 & - \\
\hline Methyl oleate & 29.4 & 2,108 & - & - & 1.5 & - \\
\hline Oleic acid & 29.9 & 2,142 & 3.3 & 9.2 & - & $\operatorname{tr}$ \\
\hline Ethyl linoleate & 30.1 & 2,159 & 1.1 & - & - & - \\
\hline Ethyl oleate & 30.2 & 2,172 & 0.9 & - & - & - \\
\hline Total (\%) & & & 92.0 & 92.9 & 89.8 & 89.8 \\
\hline
\end{tabular}

Note. RI: retention index; tr: compound present in traces (less than 0.1\%); QRN: Quercus robur native kernels; QCN: Quercus cerris native roasted kernels; QRR: Quercus robur roasted kernels; QCR: Quercus cerris roasted kernels. 
In the roasted kernels, the number of volatiles was higher and comprised a total of 32 compounds, 26 in QRR $(89.8 \%)$ and 23 in QCR $(89.8 \%)$ (Table 1). In these samples numerous furan derivatives and alkyl pyrazines were detected, with furans prevailing. The main volatile compound in QRR and QCR was furfural (51.7 and $60.6 \%$, respectively), followed by 4 -methyl furfural $(9.9 \%)$ and 5 -methyl-furfural $(8.6 \%)$ in QRR, and 5-methyl-furfural (9.4\%) in QCR. The content of palmitic acid (0.6\% in QRR and 2.2\% in QCR), and the content of other principal components in the native kernels were considerably lower in the roasted ones.

\subsection{Sensory Assessment of the Coffee-Like Beverages}

The results of the sensory assessment of the investigated roasted oak kernel beverages (QRR and QCR) are presented in Figure 1. The beverages average score for QRR was 12.9, while QCR had a slightly better average score of 13.7. Both beverages had scores near the maximum stablished for their appearance, intermediate values for taste and fullness and aroma being their weakest characteristic.



Figure 1. Results of sensory assessment of coffee-like beverages from roasted Q. robur (QRR) and Q. cerris (QCR) acorn kernels

Roasting is used to improve and alter food quality, to extend the shelf-life of foods, and to improve the processing efficiency of the subsequent treatment (Youn \& Chung, 2012). It is crucial for typical aroma formation of some products: coffee (Petisca, Pérez-Palacios, Farah, Pinho, \& Ferreira, 2013), peanuts, pumpkin seed (Siegmund \& Murkovic, 2004) and perilla seed oils (Kwon, Park, \& Yung, 2013). During the roasting process many degradation reactions occur, including the Strecker degradation, lipid peroxidation and the Maillard reaction. Products of these reactions, furans and various nitrogen-containing heterocyclic compounds, significantly contribute the aroma and flavor of many roasted products (Siegmund \& Murkovic, 2004).

Furan and furanic compounds are formed through two main pathways: lipid peroxidation and degradation of carbohydrates (Siegmund \& Murkovic, 2004). Furan derivatives are nowadays receiving special attention. They are related to the flavor of foods and beverages, providing pleasant characteristics. Furfural and furfuryl alcohol are formed during acid hydrolysis or heating of polysaccharides containing hexoses or pentoses, and occur in much fruit tea, and especially in coffee and cocoa. On the other hand, according to in vitro studies, furan derivatives are also related to potential harmful effects. Little is known about the mechanism of action in humans, and only little information is available from animal studies and additional data are needed to confirm the existence of genotoxic metabolites (Anese \& Suman, 2013; Petisca et al., 2013).

The nitrogen-containing heterocyclic compounds, including pyridines, pyrazines, and pyrroles, are well-known as Maillard reaction products and give characteristic roasted or toasted flavors to roasted coffee (Moon \& Shibamoto, 2009). Pyrazines have been reported to impart a nut-like flavor in a variety of foods, roasted and baked, or in many other types of thermally processed foods, such as roasted peanut flavor and aroma (Kwon et al., 2013). Pyrazines are also correlated with sensory attributes, such as roasty, nutty, coffee-like, woody and earthy (Siegmund \& Murkovic, 2004).

Coffee substitutes are prepared from the seeds and roots of many plants, which, like coffee beans, contain a high content of carbohydrates, proteins and other compounds with physiological activity. Upon roasting, seeds and roots generally tend to take on a coffee-like color and give a high percentage of water-soluble extract, which 
exhibits a flavor similar to that of coffee. These substitutes have been composed of chicory roots, malt, barley and rye, which are preferably used in manufacturing coffee substitutes. Apart from single constituent-based products, blends of coffee substitutes have been developed in order to improve the overall coffee-like flavor, color and resemblance to instant coffee. Nowadays, commercial blends of substitutes are predominantly consumed, especially in a soluble (instant) form. Coffee substitute blends include other various ingredients, such as dried figs, acorns, sugar beet roots, chickpeas, soy beans, dandelion roots, almonds, and asparagus. Coffee substitutes may be brewed alone, or can be added to beverages made of coffee, so they are sometimes called "coffee additives" or "coffee spices" because they provide color, bitterness or flavor to the beverage (Komes et al., 2015).

In Serbia, especially during war periods, when coffee deprivation was most pronounced, oak kernels were traditionally used as a cheap and easily available substitute for coffee (Gorunović \& Lukić, 2001; Tucakov, 1971). In this work, coffee-like beverages of roasted English and Turkish oak acorn kernels (QRR and QCR) were prepared and their sensory analysis was made. Both beverages had a good appearance, satisfying aroma and taste, and overall good acceptance. The chemical analysis showed that in the roasted samples the main volatile compounds were furan derivatives (75.5\% in QRR and $74.7 \%$ in QCR), followed by a much lower amount of pyrazines (4.2\% in QRR and $10.1 \%$ in QCR). Slight differences in their chemical composition were observed, among which the quantity of pyrazines was most prominent. This might be a reason for slightly better aroma and taste scores for QCR-beverages than QRR-beverages in our investigation. Furans were identified as the main chemical class found in ground Arabica coffee, followed by ketones, pyrazines, pyridines and pyrroles, while in espresso coffee the most presented chemicals were furans, followed by pyrazines, aldehydes and pyridines (Petisca et al., 2013).

Previously it was shown (Rakić et al., 2004, 2007) that extracts of native and roasted kernels of both investigated oak species exhibited high antioxidant activity. The activity of the roasted samples was more prominent and comparable with vitamin $\mathrm{C}$, what is explained by the presence of hydrolysable tannins in the native kernels (samples QRN and QCN). These compounds are degraded under high temperatures, causing an increase in non-tannin phenolics and gallic acid content and consequently increasing the antioxidant activity of roasted samples (Rakić et al., 2007). Furans and nitrogen-containing compounds, which are also formed during roasting, contribute to the aroma and taste of brewed oak acorn infusions.

\section{Conclusion}

Furfural, furan derivatives and pyrazines are the principal volatile components found in roasted kernels of both QR and QC types. It can be concluded that coffee-like beverages of roasted English and Turkish oak kernels have organoleptic properties that can be partially influenced with volatile constituents of the kernels. This fact, along with previous findings on their substantial antioxidant and antiradical activities, point out that these easily available, cheap, but neglected native raw materials are unquestionably well fitted into a modern functional food concept, thus there are future perspectives for their everyday use.

It can be concluded that coffee-like beverages of roasted English and Turkish oak kernels have organoleptic properties that can be partially influenced with volatile constituents of the kernels. This fact, along with previous findings on their substantial antioxidant and antiradical activities, point out that these easily available, cheap, but neglected native raw materials are unquestionably well fitted into a modern functional food concept, thus there are future perspectives for their everyday use.

\section{References}

Andrés, V., Dolores Tenorio, M., \& José Villanueva, M. (2015). Sensory profile, soluble sugars, organic acids, and mineral content in milk- and soy-juice based beverages. Food Chemistry, 173, 1100-1106. https://doi.org/10.1016/j.foodchem.2014.10.136

Anese, M., \& Suman, M. (2013). Mitigation strategies of furan and 5-hydroxymethylfurfural in food. Food Research International, 51, 257-264. https://doi.org/10.1016/j.foodres.2012.12.024

Cabrera-Vique, C., Marfil, R., Giménez, R., \& Martínez-Augustin, O. (2012). Bioactive compounds and nutritional significance of virgin argan oil-An edible oil with potential as a functional food. Nutrition Reviews, 70(5), 266-279. https://doi.org/10.1111/j.1753-4887.2012.00478.x

Fadel, H. H. M., Mageed, M. A., \& Lotfy, S. N. (2008). Quality and flavour stability of coffee substitute prepared by extrusion of wheat germ and chicory roots. Amino Acids, 34(2), 307-314. https://doi.org/ $10.1007 / \mathrm{s} 00726-006-0434-7$ 
Fernald, H., \& Kinsey, A. (1943). Edible wild plants of eastern North America. Cornwall-on-Hudson, NY: Academic Press.

Ferrari, C. K. B., \& Torres, E. A. F. S. (2003). Biochemical pharmacology of functional foods and prevention of chronic diseases of aging. Biomedicine \& Pharmacotherapy, 57, 251-260. https://doi.org/10.1016/S07533322(03)00032-5

Gorunović, M. S., \& Lukić, P. B. (2001). Farmakognozija (Vol. 97, p. 410). Belgrade: Faculty of Pharmacy, University of Belgrade.

Hill, A. R. (1937). Economic botany. NY: McGraw-Hill Book Co. Inc.

ISO 3509. (2005). Coffee and coffee products-Vocabulary.

Janković, M. (1975). Quercus L. In M. Josifović (Ed.), Flora of SR Serbia (Vol. II, pp. 77-98). Belgrade: SANU.

Jevtović, M. (1980). Pelagićev narodni učitelj. Belgrade: Sloboda.

Kemp, S. E., Hollowood, T., \& Hort, J. (2011). Sensory evaluation: A practical handbook. John Wiley \& Sons.

Komes, D., Bušić, A., Vojvodić, A., Belščak-Cvitanović, A., \& Hruškar, M. (2015). Antioxidative potential of different coffee substitute brews affected by milk addition. European Food Research and Technology, 241(1), 115-125. https://doi.org/10.1007/s00217-015-2440-Z

Kwon, T. Y., Park, J. S., \& Jung, M. Y. (2013). Headspace-solid phase microextraction-gas chromatography-tandem mass spectrometry (HS-SPME-GC-MS2) method for the determination of pyrazines in perilla seed oils: Impact of roasting on the pyrazines in perilla seed oils. Journal of Agricultural and Food Chemistry, 61(36), 8514-8523. https://doi.org/10.1021/jf402487a

Lopes, I. M. G., \& Bernardo-Gil, M. G. (2005). Characterization of acorn oils extracted by hexane and by supercritical carbon dioxide. European Journal of Lipid Science and Technology, 107, 12-19. https://doi.org/10.1002/ejlt.200401039

Moon, J.-K., \& Shibamoto, T. (2009). Role of roasting conditions in the profile of volatile flavor chemicals formed from coffee beans. Journal of Agricultural and Food Chemistry, 57(13), 5823-5831. https://doi.org/10.1021/jf901136e

Nonier, M. F., Vivasa, N., Vivas de Gaulejac, N., Absalon, C., Soulié, Ph., \& Fouquet, E. (2006). Pyrolysis-gas chromatography/mass spectrometry of Quercus sp. Wood Application to structural elucidation of macromolecules and aromatic profiles of different species. Journal of Analytical and Applied Pyrolysis, 75, 181-193. https://doi.org/10.1016/j.jaap.2005.05.006

Petisca, C., Pérez-Palacios, T., Farah, A., Pinho, O., \& Ferreira, I. M. P. L. V. O. (2013). Furans and other volatile compounds in ground roasted and espresso coffee using headspace solid-phase microextraction: Effect of roasting speed. Food and Bioproducts Processing, 91(3), 233-241. https://doi.org/10.1016/ j.fbp.2012.10.003

Petrović, S., Šobajić, S., Rakić, S., Tomić, A., \& Kukić, J. (2004). Investigation of kernel oils of Quercus robur and Quercus cerris. Chemistry of Natural Compounds, 40, 420-422. https://doi.org/10.1007/s10600-0050003-4

Raileanu, C., Lenco, G., \& Rotaru, G. (2009). Process of variance analysis-mono-factorial ANOVA method applied to study of drinks with milk and fruit juice addition. Annals Food Science and Technology, 10, 380-384.

Rakić, S., Maletić, R., Perunović, M., \& Svrzić, G. (2004). Influence of thermal treatment on tannin content and antioxidation effect of oak acorn Quercus cerris extract. Journal of Agricultural Sciences, 49, 97-106.

Rakić, S., Petrović, S., Kukić, J., Jadranin, M., Tešević, V., Povrenović, D., \& Šiler-Marinković, S. (2007). Influence of thermal treatment on phenolic compounds and antioxidant properties of oak acorns from Serbia. Food Chemistry, 104, 830-834. https://doi.org/10.1016/j.foodchem.2007.01.025

Rakić, S., Povrenović, D., Tešević, V., Simić, M., \& Maletić, R. (2006). Oak acorn, polyphenols and antioxidant activity in functional food. Journal of Food Engineering, 74, 416-423. https://doi.org/10.1016/j.jfoodeng. 2005.03.057

Sakhale, B. K., Pawar, V. N., \& Ranveer, R. C. (2012). Studies on the development and storage of whey based RTS beverage from mango cv. Kesar. Journal of Food Processing and Technology, 3, 148. https://doi.org/ 10.1016/j.foodchem.2007.01.025 
Saricicek, B. Z., \& Kilic, U. (2004). An investigation on determining the nutritive value of oak nuts. Czech Journal of Animal Science, 49, 211-219. https://doi.org/10.17221/4302-CJAS

Siegmund, B., \& Murkovic, M. (2004). Changes in chemical composition of pumpkin seeds during the roasting process for production of pumpkin seed oil (Part 2: Volatile compounds). Food Chemistry, 84(3), 367-374. https://doi.org/10.1016/S0308-8146(03)00240-1

Tucakov, J. (1971). Lečenje biljem. Belgrade: Rad.

Valero Galván, J., Jorrín Novo, J. J., Cabrera, A. G., Ariza, D., García-Olmo, J., \& Cerrillo, R. M. N. (2012). Population variability based on the morphometry and chemical composition of the acorn in Holm oak (Quercus ilex subsp. ballota [Desf.] Samp.). European Journal of Forest Research, 131(4), 893-904. https://doi.org/10.1007/s10342-011-0563-8

Youn, K. S., \& Chung, H. S. (2012). Optimization of the roasting temperature and time for preparation of coffee-like maize beverage using the response surface methodology. LWT-Food Science and Technology, 46, 305-310. https://doi.org/10.1016/j.lwt.2011.09.014

\section{Copyrights}

Copyright for this article is retained by the author(s), with first publication rights granted to the journal.

This is an open-access article distributed under the terms and conditions of the Creative Commons Attribution license (http://creativecommons.org/licenses/by/4.0/). 